\title{
Correction to: Evaluation of a new sagittal classification system in adolescent idiopathic scoliosis
}

\author{
Sidsel Fruergaard ${ }^{1,2}$ (D) Mohit J. Jain ${ }^{1} \cdot$ Lorenzo Deveza $^{1} \cdot$ David Liu $^{1} \cdot$ John Heydemann ${ }^{1} \cdot$ Søren Ohrt-Nissen ${ }^{2}$. \\ Casper Dragsted $^{1,2} \cdot$ Martin Gehrchen $^{2} \cdot$ Benny Dahl $^{1}$ on behalf of Texas Children's Hospital Spine Study Group ${ }^{1}$
}

Published online: 28 January 2020

(c) Springer-Verlag GmbH Germany, part of Springer Nature 2020

\section{Correction to: European Spine Journal https://doi.org/10.1007/s00586-019-06241-5}

Unfortunately, the names of the members of the Texas Children's Hospital Spine Study Group have not been mentioned in the published article.

Their names are:

Darrell Hanson, MD

William Phillips, MD

Frank Gerow, MD

Publisher's Note Springer Nature remains neutral with regard to jurisdictional claims in published maps and institutional affiliations.

The original article can be found online at https://doi.org/10.1007/ s00586-019-06241-5

Sidsel Fruergaard sidsel.fruergaard@gmail.com

1 Department of Orthopedics and Scoliosis Surgery, Texas Children's Hospital and Baylor College of Medicine, Houston, TX, USA

2 Spine Unit, Department of Orthopedic Surgery, Rigshospitalet, Copenhagen University Hospital, Copenhagen, Denmark 